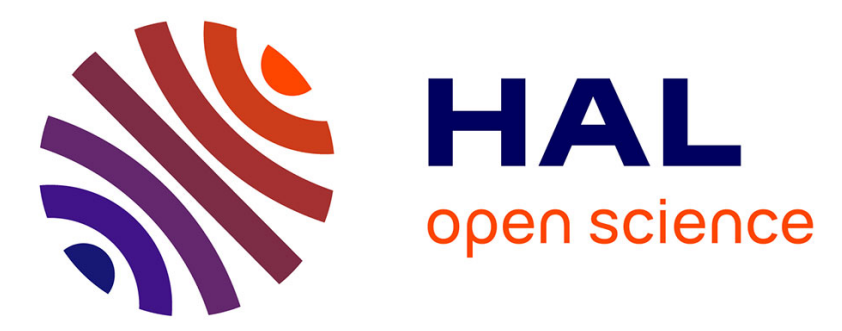

\title{
Motor expertise for typing impacts lexical decision performance
}

Tania Cerni, Jean-Luc Velay, F.-Xavier Alario, Marianne Vaugoyeau, Marieke Longcamp

\section{- To cite this version:}

Tania Cerni, Jean-Luc Velay, F.-Xavier Alario, Marianne Vaugoyeau, Marieke Longcamp. Motor expertise for typing impacts lexical decision performance. Trends in Neuroscience and Education, 2016, 5 (3), pp.130-138. 10.1016/j.tine.2016.07.007 . hal-02097752

HAL Id: hal-02097752

https://hal.science/hal-02097752

Submitted on 8 Jul 2019

HAL is a multi-disciplinary open access archive for the deposit and dissemination of scientific research documents, whether they are published or not. The documents may come from teaching and research institutions in France or abroad, or from public or private research centers.
L'archive ouverte pluridisciplinaire HAL, est destinée au dépôt et à la diffusion de documents scientifiques de niveau recherche, publiés ou non, émanant des établissements d'enseignement et de recherche français ou étrangers, des laboratoires publics ou privés. 
Neuroscience and Education

Elsevier Editorial system(tm) for Trends in

Manuscript Draft

Manuscript Number:

Title: Motor expertise for typing impacts lexical decision performance

Article Type: Research Paper

Section/Category: Other Psychophysiology

Keywords: Typing, lexical decision, expertise, interkeystroke intervals

Corresponding Author: Dr. Jean-Luc Velay,

Corresponding Author's Institution:

First Author: Tania Cerni, PhD

Order of Authors: Tania Cerni, PhD; Jean-Luc Velay; François-Xavier Alario, PhD; Marianne Vaugoyeau, PhD; Marieke Longcamp, PhD

Abstract: The shift of writing habits in the general population calls for a better understanding of the possible consequences of typing practice on language processing. To address this issue, we have built a set of words and pseudowords differing by their ratio of bimanual transitions between letters, an index of typing difficulty. An effect of typing difficulty was observed in expert participants who were actually typing the items, and not in non-expert typists. We then tested whether word recognition performance, measured with the task of lexical decision, was impacted by typing expertise and the typing difficulty of words. Lexical decision latencies varied as a function of typing motor difficulty. The effect was mostly driven by lexical decision times for pseudowords. This constitutes a first suggestion that motor representations built during the acquisition and practice of the typing skill have a collateral effect on visual recognition processes leading to lexical decision.

Suggested Reviewers: 


\section{Motor expertise for typing impacts lexical decision performance}

Tania Cerni, Jean-Luc Velay, F.-Xavier Alario, Marianne Vaugoyeau \& Marieke Longcamp

\section{Tania Cerni}

Department of Psychology and Cognitive Science, University of Trento

Corso Bettini, 31 - 38068 Rovereto, Italy.

Phone: +39 0464808668; Email: tania.cerni@unitn.it

Jean-Luc Velay

CNRS - Aix-Marseille Université, Laboratoire de Neurosciences Cognitives, UMR 7291 CNRS, FR 3C FR 3512, Centre Saint-Charles, Case C, 3 place Victor Hugo 13331 Marseille cedex 3, FRANCE

Phone: +33 413551174; Email: jean-luc.velay@univ-amu.fr

Francois-Xavier Alario

CNRS - Aix-Marseille Université, Laboratoire de Psychologie Cognitive, UMR 7290 CNRS, FR 3C FR 3512, Centre Saint-Charles, Case D, 3 place Victor Hugo 13331 Marseille cedex 3, FRANCE

Phone: +33 413550972; Email: francois-xavier.alario@univ-amu.fr

Marianne Vaugoyeau

CNRS - Aix-Marseille Université, Laboratoire de Neurosciences Cognitives, UMR 7291 CNRS, FR 3C FR 3512, Centre Saint-Charles, Case C, 3 place Victor Hugo 13331 Marseille cedex 3, FRANCE

Phone: +33 413550902; Email: marianne.vaugoyeau@univ-amu.fr

\section{Marieke Longcamp}

CNRS - Aix-Marseille Université, Laboratoire de Neurosciences Cognitives, UMR 7291 CNRS, FR 3C FR 3512, Centre Saint-Charles, Case C, 3 place Victor Hugo 13331 Marseille cedex 3, FRANCE

Phone +33 413551086; Email: marieke.longcamp@univ-amu.fr 


\begin{abstract}
The massive shift of writing habits in the general population calls for a better understanding of the possible consequences of typing practice on language processing, including reading. To address this issue, we have built a set of words and pseudowords differing by their ratio of bimanual transitions between letters, an index of typing difficulty. The items with few bimanual transitions are difficult to type, whereas those with many transitions are easy. An effect of typing difficulty was observed in expert participants who were actually typing the items, and not in non-expert typists. We then tested whether word recognition performance, measured with the task of lexical decision, was impacted by typing expertise and the typing difficulty of words. Lexical decision latencies varied as a function of typing motor difficulty. The effect was mostly driven by lexical decision times for pseudowords. This constitutes a first suggestion that motor representations built during the acquisition and practice of the typing skill have a collateral effect on visual recognition processes leading to lexical decision. Changing writing habits could therefore impact reading processes.
\end{abstract}

Keywords: Typing, lexical decision, expertise, interkeystroke intervals 


\section{Introduction}

Handwriting is still widely taught in elementary schools throughout the world. It is a long and, for some children, painful learning experience which has always been mandatory at school since it has always been the most used form of written communication. Nowadays, typing is clearly becoming the dominant writing modality in adulthood and perhaps even earlier. This massive shift of practice in the adult population brings into question the legitimacy of handwriting teaching at school. Indeed, to many people's minds, handwriting is nothing more than a tool at the service of written communication and, when a tool becomes obsolete, it should be replaced by a more modern one. According to this point of view, handwriting should be replaced by typewriting at school. Is handwriting no more than a tool however, and what cognitive changes might occur if typing should takes its place at school? What, if any, would be the possible consequences of typing practice on language processing in general, and on reading in particular?

Although reading and writing have typically been studied separately, as if they were encapsulated systems, some researchers have hypothesized the existence of specific directional influences of the motor aspects of writing on reading, the rationale being that reading acquisition and practice is supported by contemporaneous performance of writing gestures [1-3].

Empirical evidence has been reported showing that knowledge of handwriting movements favors the visual recognition of letters and the associated neural substrates [4-6; for a review see 7]. Letter recognition being one of the earliest steps in word reading, motor knowledge is likely to affect skilled reading [8-9]. Beyond single letter identification, it is nonetheless still impossible to affirm that teaching typing instead of handwriting would have an effect on reading whole words (but see [10]).

When compared to handwriting, typing practice has been revealed to be less efficient in single character recognition, presumably because the movement performed in striking a given key bears 
no relationship to the shape of the character to be recognized [4-5, 11-12]. Empirical studies comparing the effects of typing and handwriting practice on letter recognition nonetheless suffer from the same limitation: For ethical or practical reasons, training has been limited to short time periods, usually a few weeks. This limitation has two main consequences, at the linguistic and motor levels. As regards the linguistic level, the children or adult participants were not taught for long enough to allow the assessment of their true lexical knowledge and reading capacity. As concerns the motor level, the participants tested were hunt-and-peck typists who displayed poor typing skills and variable associations between fingers and keys and thus any possible benefit of typing on reading could not be tested.

To overcome these limitations, another strategy consists of testing whether expert typists exhibit reading capacities which are somehow influenced by their typing habits. Of course, expert typists have been taught handwriting but usually they also learned typing early at school and, because of their professional activity, they type much more often than they write by hand.

Typing expertise is characterized by very strong and systematic associations which rely on stable motor representations that bind systematically with visual representations of the characters [13-14]. Rieger [13] showed for instance that in a task involving the visual display of single letters, and although the task bore no direct relationship to typing, the finger responses that matched the letters were facilitated in skilled typists, but not in hunt-and-peck typists, suggesting stable motorperceptual interactions in the former population. Furthermore, and crucial to our purposes, while the shape of the characters is fundamental in handwriting, a critical dimension of typing is the sequence of keystrokes corresponding to the sequence of letters composing the words. One of the major differences between expert and hunt-and-peck typists is that the former use both hands, the right hand to hit the keys on the right part of the keyboard and the left hand for the keys on the left part, whereas the latter do not respect this systematic rule in typing and more often use their dominant hand whatever the position of the key. It has been shown that choosing between two fingers of 
different hands is easier than choosing between two fingers of the same hand [15]. Furthermore,

alternating bimanual hits give rise to a higher and less variable typing rate than when using a single hand [16]. These motor reasons might explain why, in experts, a remarkably stable motor feature of typing movements is that cross-hand (bimanual) inter-keystroke intervals are shorter than withinhand (unimanual) inter-keystroke intervals [14, 17-19]. This motor transition effect implies that, for an expert, a word containing a majority of bimanual transitions is much easier to type than a word containing mostly unimanual transitions [20]. This pattern is not present in novice typists [21].

A few studies suggest that, in experts, this bimanual motor facilitation has a counterpart in the perceptual processing of letter pairs. Van Den Bergh, Vrana and Eelen [22], and Beilock and Holt [23] showed that skilled typists spontaneously prefer pairs of letters usually typed with two different fingers relative to pairs usually typed with the same finger. Similar effects were also observed in a memory task [24]. This suggests that typing expertise can lead to an activation of specific motor patterns in perceptual tasks provided that the associated motor representations are stable, but the evidence is scarce and its application to visual recognition is not straightforward.

The aim of the present study was therefore to directly test whether word recognition, as indexed by the paradigmatic task of lexical decision, was impacted by typing expertise. We designed a set of French words in which we manipulated the number of cross- and within-hand transitions and counterbalanced other relevant properties. For the expert typists, these words varied according to their writing difficulty between 'easy' words, those with many bi-manual transitions, and 'difficult' words, those with few bi-manual transitions. We then tested whether lexical decision performance for those words and for matched pseudowords showed a differential effect of motor difficulty in expert and non-expert typists. Observing increased lexical decision times for items which were difficult to type would be a strong suggestion that typing knowledge is activated in the course of visual word recognition. Such an effect is expected for expert but not for non-expert typists. 


\section{Methods}

Participants. The experiment was designed to include sixteen participants per group. This number was set to optimize the counter-balancing of the tasks and finger / response button matching. To reach this number, twenty expert typists (formally trained in touch-typing), French native speakers, had to be tested. Four of them produced errors rates exceeding $40 \%$ in the typing task of the trials and had to be replaced by another 4 typists. The control group was then composed of 16 participants without major experience of typing, selected to match the typists for age, gender, education and handedness. Non-experts usually typed with a maximum of three fingers per hand and lacked any formal training in a standard typing method. None of the participants in the control group had to be discarded but one turned out to be an expert (see below).

For all participants, we checked the declared degree of typing expertise with a questionnaire on their writing habits (Table 1) and a computerized typing pretest, programmed with Presentation ${ }^{\circledR}$ 16.3 (www.neurobs.com). The test yielded estimates of typing rate and accuracy based on two short texts that participants had to transcribe at their normal typing rate. Accuracy was defined on a per word basis. Typing rate was calculated as the rate of words (5 characters) typed per minute [25]. Finally, we recorded videos of the participants while they did the typing pretest to ensure that experts and non-experts used the number and position of fingers expected for each group.

One of the non-expert participants was finally re-assigned to the experts group, given her very good typing performance and her use of 10 fingers, despite her self-report of typing habits. Eventually, then, the expert group included 17 participants ( 1 male/16 female) and the control group included 15 participants ( 1 male/14 female; Table 1$)$.

Insert Table 1 about here 


\section{Stimuli.}

We determined what the rules are regarding the letters that should be hit by the right and the left hands in French expert typists. As can be seen in figure 1, 15 letters are hit using the left and 11 using the right hand on a French keyboard. We discarded the left-hand letters "w", "x", "c" and "v" because these have no right hand counterpart in the AZERTY keyboard.

Insert Fig 1 about here

We searched the 'Lexique' database [26] for words that were typed with variable proportions of bimanual typing transitions on the standard French AZERTY keyboard (see Table 2).

Insert Table 2 about here

The 120 selected words were all 6 to 8 letters long. The experimental words were divided into 15 transition ratio categories (from 14\%, for example "pompiste" to $85 \%$, for example "habituel"; bold letters being typed with the right hand). Across these 15 categories, the items were matched for: the hand used to type the first letter, the average number of letters typed with the left and right hand, lexical frequency, number of syllables and phonemes, presence / number of homophones and homographs, frequency of bigrams, number of orthographic and phonological neighbors (Levenshtein distance), and lastly orthographic regularity. Table 3 summarizes these properties, and shows that only bigram frequency and orthographic Levenshtein distance (old20) were significantly different across transition ratio categories.

Insert Table 3 about here 
For the lexical decision task, we also prepared a list of 120 pseudowords, created by changing

one letter from each of the experimental words. The substitute letter respected the bimanual transition structure of the base-word and led to a minimal trigram frequency given its position, of 10.

To these strictly controlled lists of stimuli, we added 36 words and 36 pseudowords with transition ratios of 0 and $100 \%$ (i.e. typed with a single hand or hand transitions at every letter). These served as fillers and were not further analyzed, as it was not possible to identify in the 'LEXIQUE' database (or toolbox) sets of words with 0 and $100 \%$ transitions that respected the matching criteria for the experimental items as described above.

Procedure. This report is part of a larger study of written language processing in expert and non-expert typists, where each participant was involved successively in 4 different tasks that used the same set of words: a typing to dictation task, a handwriting to dictation task, a lexical decision task and a spelling task. Task order was counter-balanced across participants in a pseudo-random manner (Latin square). Here we report the specific methods and results of the tasks that permitted the testing of our hypothesis: the typing to dictation task and the lexical decision task. We checked that task order had no significant effect on performance in the two tasks of interest, and that it did not interact with the main factors.

Using a high quality sound card, words and pseudowords were dictated to the participant who was wearing headphones. The audio stimuli were recorded from a native female French speaker in an anechoic room and segmented with Audacity 2.0.3. For the typing task, a high quality video card and a CRT screen with a $70 \mathrm{~Hz}$ refresh rate were used to display the words typed by the participant. In both tasks, a QWERTY DirectIN Millisecond Accurate Keyboard (http://www.empirisoft.com/), adapted as an AZERTY keyboard with stickers on the keys, was used for collecting responses. Stimulus presentation and response recordings were controlled by the software Presentation® 16.3 (http://www.neurobs.com/). 


\section{Tasks.}

Auditory Typing task. In this task, participants had to type the dictated words. Only words were presented, because of the impossibility of writing dictated pseudowords without spelling errors. The words were dictated one per trial in a random order. Each trial started with a fixation cross in the center of the screen, along with the auditory word presentation. Participants were instructed to start typing as soon as they had identified the word. Typed letters were displayed on-line on the center of the screen, replacing the fixation cross. The duration of each trial (stimulus plus input) was set to $4000 \mathrm{~ms}$ for experts and $5000 \mathrm{~ms}$ for non-experts. The task was split into two blocks of 60 words separated by a brief pause.

A response was considered incorrect if it included the backspace or a wrong key. The remaining correct responses were used to calculate the response times (RTs: time between the beginning of the trial and the first keystroke) and the average interkeystroke interval (IKI) per trial.

Visual Lexical decision task. Participants were presented with the item (a word or a pseudoword) and they had to decide as quickly and accurately as possible whether the visually presented letter string formed a word they knew. Stimuli were presented in Times New Roman in the center of the screen. The size of the words covered 3 to 4 degrees of the visual field. At the beginning of each trial a fixation cross appeared at the center of the screen for $500 \mathrm{~ms}$; then a word or a pseudo-word was presented until the response was given. After the response, a blank screen was displayed for $1000 \mathrm{~ms}$. The order of presentation of words and pseudowords was randomized and differed across participants. Responses were given by means of the two F1 and F2 keys of the same Millisecond Accurate Keyboard, covered with a plastic board so that only the 2 response keys (F1 and F2) were visible. Participants used their right index (F1) and right middle fingers (F2), and the association between finger and response (word vs pseudoword) was counterbalanced across participants. Both response times and error rates were collected. 


\section{Data processing and statistical analysis.}

In the Typing task, we excluded the errors (18.7\% for the expert group; $13.8 \%$ for the nonexperts group). Outliers were considered after error detection. For each participant, response times above and below 2.5 standard deviations from their mean were considered outliers and discarded from the data-set $(0.03 \%$ replacements for the experts, and $0.03 \%$ for the non-experts). The same was done with IKIs (18.2\% replacements for the expert group, and $16.8 \%$ for the non-experts group - tot $17.5 \%)$.

In the Lexical decision task, errors in discriminating words and pseudowords were discarded from the dataset (4.5\% for the expert group; $4.2 \%$ for the control group - tot $4.4 \%$ ).

Outliers were identified on the sets of correct responses, for each participant as reaction time (RT) above and below 2.5 standard deviations from the mean $(2.7 \%$ for the expert group; $2.5 \%$ for the control group - tot $2.6 \%$ for lexical decision) and the corresponding RTs were also discarded from the dataset.

The resulting RTs and IKIs were log-transformed [28] and examined with linear mixed regression models ([28-29], software R, package lmerTest for models processing and p-values and package LMERConvenienceFunctions for graphical representations). We constructed models for each task separately. In all models, subjects and items were considered as random-effects while group (expert vs non-expert), bimanual transition ratio and the interaction between the two were considered as fixed effects. Bimanual transition ratio values were modeled as a continuous predictor. Furthermore we included in the models all the linguistic and task-dependent variables that reached significance, discarding those that failed to reach significance.

Error rates in both tasks were also analyzed using logistic regression models with the same predictor structure as the models used for RTs. The results are reported only when significant. 


\section{Results}

\section{Typing task.}

Errors. The error analysis showed a significant effect of group $(\beta=-0.59, \mathrm{SE}=0.28, \mathrm{z}=-2.06$, $\mathrm{p}<0.05)$, the experts making more errors than the non-experts.

Response times. In the final model we included the number of phonemes in the word, frequency, the bigrams frequency, the orthographic Levenshtein distance (old20) and the hand used to type the first letter. The only effect that reached significance was the difference between the groups (fig. 2): As expected, the experts exhibited a shorter time to type the first letter of the words than the non-experts $(\beta=0.2, \mathrm{SE}=0.04, \mathrm{t}=5.5, \mathrm{p}<0.001)$. However, no effect of difficulty (bimanual transition ratio) was observed, and the group by difficulty interaction did not reach significance.

IKIs. In the final model we included the number of letters in the word, frequency, bigrams frequency, the orthographic Levenshtein (old20) distance and the hand used to type the first letter. All the variables of interest reached significance. Although the analysis was actually done taking into account the 15 categories of bimanual transitions, for the sake of clarity the data from the 15 categories have been combined into 3 categories of difficulty: difficult words (with a low ratio of bimanual transition, 14 to $33 \%$ ), medium words (with a medium ratio of bimanual transition, 40 to $60 \%$ ), and easy words (66 to $85 \%$ of bimanual transitions). As can be seen in figure 2, the IKIs were shorter in expert than in non-expert typists $(\beta=0.2, \mathrm{SE}=0.06, \mathrm{t}=3.3, \mathrm{p}<0.01)$. Furthermore, IKIs were modulated by the typing difficulty $(\beta=-0.002, \mathrm{SE}=0.0003, \mathrm{t}=-6.7, \mathrm{p}<0.001)$, although in an opposite manner between experts and non-experts: The interaction between group and difficulty was highly significant: $\beta=0.003, \mathrm{SE}=0.0002, \mathrm{t}=16.6, \mathrm{p}<0.001$. 
Splitting the two groups into two separate databases allowed us to test whether the effect of difficulty was significant within each group. The effect of difficulty was highly significant for both groups, yet in opposite directions: In experts, IKIs increased as the difficulty increased $(\beta=-0.002$, $\mathrm{SE}=0.0003, \mathrm{t}=-5.7, \mathrm{p}<0.001)$ whereas in non-experts IKIs decreased as difficulty increased $(\beta$ $=0.001, \mathrm{SE}=0.0003, \mathrm{t}=5.1, \mathrm{p}<0.001)$. In other words, in the expert typists, the greater the number of bimanual transitions in the words, the lower the difficulty to type them, whereas the reverse pattern was obtained in the non-expert typists. The complete results of the models are reported in appendix (Table A1).

\section{Lexical Decision}

We included in the model: trial rank, frequency (of the word or of the base-word for pseudowords [31]) and number of letters.

Detailed effects on RTs are reported in appendix (Table A2). As expected, the standard lexicality effect was in evidence: pseudowords were associated with longer RTs than words (787 ms $(\mathrm{sd}=219) \& 694 \mathrm{~ms}(\mathrm{sd}=189)$ respectively, $\beta=-0.16, \mathrm{SE}=0.03, \mathrm{t}=-5.9, \mathrm{p}<0.001)$. As a whole, expert and non-expert typists responded at the same speed in the lexical decision task $(732 \mathrm{~ms}$ ( $\mathrm{sd}=$ 177) \& $750 \mathrm{~ms}(\mathrm{sd}=240)$, respectively, ns). Finally, no difficulty effect was observed.

However, the interaction between group and difficulty was significant $(\beta=0.0006, \mathrm{SE}=0.0003$, $\mathrm{t}=2.45, \mathrm{p}<0.05)$, meaning that the difficulty effect was different in experts and non-experts. Furthermore, the Lexicality by group by difficulty two-way interaction approached significance ( $\beta$ $=-0.0007, \mathrm{SE}=0.0004, \mathrm{t}=-1.8, \mathrm{p}=0.06)$. In other words, the effect of difficulty was different in experts and non-experts and varied between words and pseudowords. In order to estimate more precisely the interaction between group and difficulty, we analyzed the word and pseudoword datasets separately. 
Words. The model included the trial rank, frequency, and the orthographic Levenshtein distance

(old20). The analysis revealed neither a significant group effect, nor a difficulty effect, nor a significant group by difficulty interaction.

Pseudowords. The model included the trial rank and the number of letters in the word. The analysis revealed neither a significant group effect, nor a difficulty effect. However, the group by difficulty interaction reached significance $(\beta=0.0006, \mathrm{SE}=0.0002, \mathrm{t}=2.6, \mathrm{p}<0.01)$. As can be seen in figure 3, in the lexical decision for pseudowords, the same trend as in the words typing task can be observed: In experts, the detection of pseudowords tended to slow down as the typing difficulty increased, while in non-experts the trend was opposite.

Insert Fig. 3 about here

\section{Discussion}

The results of this experiment can be summarized as follows:

1- in the typing task, as expected, the experts were faster than the non-experts to hit the first letter of the words (response time) and to type the following letters (IKIs),

2- in the typing task, the experts displayed the 'difficulty' effect: They were faster to type the 'easy' words, those involving many bimanual transitions, and slower to type the 'difficult' words. The non-experts showed the opposite pattern.

3- in the lexical decision task, both groups had the same overall mean RT but the 'typing difficulty' had a different impact on RTs for pseudowords in experts and non-experts. In experts, it took longer to identify the difficult pseudowords than the easy ones. In non-experts, the opposite trend was observed. 
The first two results confirm that the two groups who participated to this experiment actually had a different level of expertise as regards typewriting. The experts typed the words more quickly and they, in particular, showed the expected difficulty effect: they typed the 'easy' words, those composed of a sequence of letters involving both hands alternately, more quickly than the 'difficult' words, i.e. those involving few alternations between hands. It is worth noting that this difficulty effect only affected motor execution and had no influence on motor preparation since it was not present in the response times. It thus resulted from a motor effect linked to the advantage of using both hands instead of one [15-16], and not from some central cognitive / linguistic processes related to the spelling / meaning of the word. Therefore, we may guess that if pseudowords had been typed in the present experiment, the same difficulty effect would have been observed.

Surprisingly, and at variance with the hypothesis of unreliable strategies in non-experts [21], the typing difficulty systematically affected the IKIs of this group, yet in the opposite direction. The video recordings we made during typing revealed that non experts use their right hand to type the great majority of the letters with the occasional recruitment/ involvement of the left hand, presumably when the coordination of right hand fingers was too demanding. In this way, most of the transitions between letters become unimanual for non-experts. When only the right hand is used, the IKIs depend mostly on the distance between successive keys: the longer the distance, the greater the IKI. The distance separating the keys of the left and right side of the keyboard, which are hit by different hands in experts (bimanual transition), are obviously longer than those separating keys usually hit by the same hand (unimanual transition). This could explain why IKIs were larger in non-experts for the easy words, in contrast to experts.

This differential effect on motor execution in typing provides the groundwork for the main result of the study (result 3), namely that the motoric difficulty during typing had a significant 
perceptual effect on the visual lexical decision task. In other words, accessing the mental lexicon to decide whether a letter string constitutes a word somehow depends on the motor representations associated with the usual production of that same word on the keyboard. Writing habits thus influence linguistic processes. Although the present experiment was designed to evidence an effect of motor knowledge on lexical decision rather than to identify the locus of this effect in the lexical decision processes, two hypotheses can be drawn to account for our results: First, the influence of typing knowledge could stem from an early stage of orthographic processing, where letter strings are visually processed. Given previous evidence of motor-perceptual interactions for written visual stimuli at the level of single letters or letter pairs [7, 22-24], it is possible that in experts, visual perception of letter strings triggers the parallel activation of associated patterns of hand and finger typing movements, which could in turn exert an influence on the recognition processes. The stability of the motor patterns for typing would accordingly modulate the RTs.

The second and not mutually exclusive possibility is that over-training of the typing motor skills impacts written language processing at a higher level, through linguistic components that are common to both reading and spelling. This interpretation would imply two assumptions. First, the execution of the motor response in written production is not an isolated process, but is in fact carried out in strong interaction with the upstream (orthographic) spelling processes [32-34]. The repetitive performance of peripheral writing execution could shape and influence spelling procedures. Secondly, there must be some components common to the cognitive architectures of reading and spelling [35-37]. Despite a tradition of separate investigations of reading and writing, some authors assume shared cognitive components such as the orthographic and phonological lexicons [37-38] or the graphemic buffer [39-41]. In the specific case of typing, Purcell, Napoliello and Eden [42] have recently shown that brain regions known to process orthography and phonology of single words are commonly activated by reading and typed spelling. 
Although the effect of typing difficulty was significant overall, it was driven mostly by pseudoword RTs. This selective effect on pseudowords is puzzling: It could be a consequence of the standard lexicality effect, with greater RTs to pseudowords than to words. It is thus possible that a longer cognitive (linguistic) processing in the case of pseudowords affords motor representations more time to be strongly activated and to be functionally relevant. This account is in keeping with the finding of a rather late timing of the activation of motor representations in cases of embodied visual perception [43-44].

Another important aspect is that pseudoword processing generates grapheme to phoneme conversion procedures which rely more on the activation of sub-lexical pathways involving single letters or letter pairs, than of a lexical pathway $[41,45]$. Motor-perceptual interactions occurring at the level of single letters or letter pairs are more likely to occur in the case of pseudowords. The same conclusion was reached in a recent study in which transcranial magnetic stimulation (TMS) over the premotor dorsal cortex, a main region of the writing network, during a lexical decision task increased RTs to pseudowords without affecting word recognition [46]. The authors interpreted this specific effect by the assumption that pseudowords are processed serially, at a sublexical level, while words are processed globally at a lexical level.

To conclude, in terms of letter identification, it has been previously shown that handwriting was better than typing (see [7] for a review). It was then suggested that reading might be affected in persons able to type but not to handwrite. However, these studies did not really address reading processes, at least at the word level (except to some extent [10]). In the present study, we took the opposite view: We decided to check whether word recognition would be modified by typing habits and we compared expert and non-expert typists in a word identification task. The results suggest that motor representations built during training and practice of the typing skill have a perceptual / cognitive effect when words are processed. The impact was limited to pseudowords however, and this point needs further investigation. In addition, we have compared adults who are either expert in 
typing or not, but all were taught how to handwrite, therefore the group differences in term of cognitive processes involved was probably not as significant as compared to persons who are only able to type. Nevertheless, besides the theoretical implications for current models of reading, this finding raises practical questions about introducing typing instead of handwriting at school $[3,47]$.

\section{Acknowledgements}

We thank S. Pinet, the members of the DA2M group and J. Ziegler for comments on the manuscript, D. Wood (English at your Service, www.eays.eu) for revising the English. This work, carried out within the Labex BLRI (ANR-11-LABX-0036), has benefited from support from the French Government, managed by the French National Agency for Research (ANR), under the project title Investments of the Future AMIDEX (ANR-11-IDEX-0001-02) 


\section{References}

1 Tan, L.H., Spinks, J.A., Eden, G.F., Perfetti, C.A., \& Siok, W.T. (2005). Reading depends on writing, in Chinese. Proceedings of the National Academy of Sciences of the United States of America, 102 (24), 8781-8785.

2 James, K.H., \& Engelhardt, L. (2012). The effects of handwriting experience on functional brain development in pre-literate children. Trends in Neuroscience and Education, 1(1), 32-42.

3 Mikulak, A. (2014). Getting it in writing. Writing in the old-fashioned way may enhance learning and memory. APS Observer, 27(7), September 2014.

4 Longcamp, M., Anton, J. L., Roth, M. \& Velay, J. L. (2003) Visual presentation of single letters activates a premotor area involved in writing. NeuroImage 19, 1492-1500.

5 James, K.H., \& Atwood, T.P. (2008). The role of sensori-motor learning in the perception of letter-like forms: tracking the causes of neural specialization for letters. Cognitive Neuropsychology, 26(1), 91-110.

6 James, K.H. (2010) Sensori-motor experience leads to changes in visual processing in the developing brain, Developmental Science, Vol. 13, N², 279-288.

7 Velay, J.L., Longcamp, (2013) M. Motor Skills and Written Language Perception: Contribution of Writing Knowledge to Visual Recognition of Graphic Shapes. In Y. Coello and A. Bartolo (Eds); Language and Action in Cognitive Neuroscience (pp 161-177). New York, Taylor and Francis

8 Anderson, S.W., Damasio, A.R., \& Damasio, H. (1990). Troubled letters but not numbers: Domain specific cognitive impairments following focal damage in frontal cortex. Brain, 113(3), 749-766.

9 Tan, L.H., Xu, M., Chang, C.Q., \& Siok, W.T. (2012). China's language input system in the digital age affects children's reading development. Proceedings of the National Academy of Sciences of the United States of America, 110(3), 1119-1123.

10 Kiefer, M., Schuler, S., Mayer, C., Trumpp, N.M., Hille, K., and Sachse, S. (2015) Handwriting or Typewriting? The Influence of Pen-or Keyboard-Based Writing Training on Reading and Writing Performance in Preschool Children, Advances in Cognitive Psychology, Vol. 11(4), $136-146$

11 Longcamp, M., Anton, J.L., Roth, M., \&Velay, J.L. (2005). Premotor activations in response to visually presented single letters depend on the hand used to write: a study on left-handers, Neuropsychologia, 43(12), 1801-1809. 
12 Longcamp, M., Boucard, C., Gilhodes, J.C., Anton, J.L., Roth, M., Nazarian, B., \&Velay, J.L. (2008). Learning through hand- or typewriting influences visual recognition of new graphic shapes: behavioral and functional imaging evidence. Journal of Cognitive Neuroscience, 20(5), 802-815.

13 Rieger, M. (2004).Automatic Keypress Activation in Skilled Typing. Journal of Experimental Psychology: Human Perception and Performance, 30(3), 555-565.

14 Rumelhart, D.E., \& Norman, D.A. (1982).Simulating a skilled typist: A study of skilled cognitive-motor performance. Cognitive science, 6(1), 1-36.

15 Hasbroucq, T., Mouret, I., Seal J. \& Akamatsu M. (1995) Finger Pairings in Two-Choice Reaction Time Tasks: Does the Between-Hands Advantage Reflect Response Preparation? Journal of Motor Behavior Volume 27, Issue 3,

16 Helmuth, L. and Ivry, R. (1996) When Two Hands Are Better Than One: Reduced Timing Variability During Bimanual Movements, Journal of Experimental Psychology: Human Perception and Performance, Vol. 22, No. 2, 278-293.

17 Shaffer, L.H. (1976). Intention and performance. Psychological Review, 83(5), 375-393.

18 Ostry, D.J. (1983). Determinants of interkey times in typing. In W.E. Cooper (Ed.), Cognitive aspects of skilled typewriting (pp. 225-246).New York, NY: Springer New York.

19 Cerni T, Longcamp M, Job R. Two thumbs and one index: A comparison of manual coordination in touch typing and mobile typing. Acta Psychologica (in press)

20 Gentner, D.R., Grudin, J., \& Conway, E. (1980).Finger movements in transcription typing (Tech. Rep. 8001). La Jolla, Calif.: University of California at San Diego, Center for Human Information Processing.

21 Larochelle, S. (1983).A comparison of skilled and novice performance in discontinuous typing. In W.E. Cooper (Ed.), Cognitive aspects of skilled typewriting (pp. 67-94).New York, NY: Springer New York.

22 Van den Bergh, O., Vrana, S, \& Eelen, P. (1990).Letters from the heart: Affective categorization of letter combinations in typists and nontypists. Journal of Experimental Psychology:

Learning, Memory and Cognition, 16(6), 1153-1161.

23 Beilock, S.L, \& Holt, L.E. (2007).Embodied preference judgments. Can likeability be driven by the motor system? Psychological Science, 18(1), 51-57.

24 Yang, S.J., Gallo, D.A., \&Beilock, S.L. (2009).Embodied memory judgments: A case of motor fluency.Journal of Experimental Psychology: Learning, Memory, and Cognition, 35(5), 13591365. 
25 MacKenzie, I.S. (2013). A note on calculating text entry speed. Retrieved from http://www.yorku.ca/mack/RN-TextEntrySpeed.html

26 New B., Pallier C., Ferrand L., Matos R. (2001). Une base de données lexicales du français contemporain sur internet: LEXIQUE, L'Année Pschologique, 101, 447-462.

27 Yarkoni, T., Balota, D., Yap, M. (2008) Moving beyond Coltheart's N: A new measure of orthographic similarity, Psychonomic Bulletin \& Review, 15 (5), 971-979 doi: 10.3758/PBR.15.5.971

28 Bayen, R.H. (2008). Analyzing linguistic data. A practical introduction to statistics using $R$. Cambridge University Press

29- Baayen, R. H., Davidson, D. and Bates, D. M. (2008). Mixed-effects modeling with crossed random effects for subjects and items. Journal of Memory and Language, 59(4), 390-412.

30 Morey, R.D. (2005). Confidence Intervals from Normalized Data: A correction to Cousineau. Tutorials in Quantitative Methods for Psychology, 4, 61-64.

31 Perera, M., Rosa, E., \&Gòmez, C. (2005). The frequency effect for pseudowords in the lexical decision task. Perception \& Psychophysics, 67(2), 301-314.

32 McCloskey, M., Badecker, W., Goodman - Schulman, R. A., \& Aliminosa, D. (1994). The structure of graphemic representations in spelling: Evidence from a case of acquired dysgraphia. Cognitive Neuropsychology, 11, 341-392.McCloskey et al

33 Delattre, M., Bonin, P., \& Barry, C. (2006). Written spelling to dictation: Sound-to-spelling regularity affects both writing latencies and durations. Journal of Experimental Psychology: Learning, Memory, and Cognition, 32, 1330-1340.Delattre et al

34 Roux, S., McKeeff, T. J., Grosjacques, G., Afonso, O. \& Kandel, S. The interaction between central and peripheral processes in handwriting production. Cognition 127, 235-241 (2013).Roux et al

35 Hillis, A., \& Rapp, B. (2004). Cognitive and neural substrates of written language comprehension and production. The new cognitive neurosciences, 3, 755-88.

36 Philipose, L. E., Gottesman, R. F., Newhart, M., Kleinman, J. T., Herskovits, E. H., Pawlak, M. A., Marsh, E. B., Davis, C., Heidler-Gary, J. and Hillis, A. E. (2007), Neural regions essential for reading and spelling of words and pseudowords. Ann Neurol., 62: 481-492. doi: 10.1002/ana.21182

37 Rapp, B., \& Lipka, K. (2011).The literate brain: The relationship between reading and spelling. Journal of Cognitive Neuroscience, 23(5), 1180-1197. 
38 Rapcsak, S.Z., Beeson, P.M., Henry, M.L., Leyden, A., Kim, E., Rising, K., Andersen, S., Cho,

H. (2009) Phonological dyslexia and dysgraphia: Cognitive mechanisms and neural substrates, Cortex, Volume 45, Issue 5, May 2009, Pages 575-591.

39 Caramazza, A., Capasso, R., \& Miceli, G. (1996). The role of the graphemic buffer in reading. Cognitive Neuropsychology, 13(5), 673-698.

40 Tainturier, M. J., \& Rapp, B. (2001). The Spelling Process. In B. Rapp (Ed.), What deficits reveal about the human mind/brain: A handbook of cognitive neuropsychology. Philadelphia: Psychology Press.

41 Perry, C., Ziegler, J.C., \& Zorzi, M. (2007). Nested incremental modeling in the development of computational theories: the CDP+ model of reading aloud. Psychological Review, 114(2), 273-315.

42 Purcell, J.J., Napoliello, E.M., \& Eden, G.F. (2011). A combined fMRI study of typed spelling and reading. Neuroimage, 55(2), 750-762.

43 Wamain Y, Tallet J, and Zanone PG, Longcamp M. (2011) Biological geometry perception: visual discrimination of eccentricity is related to individual motor preferences. PLOS one. 6(1):e15995

44 Nishitani, N., Avikainen, S. and Hari, R. (2004), Abnormal imitation-related cortical activation sequences in Asperger's syndrome. Ann Neurol., 55: 558-562. doi: 10.1002/ana.20031

45 Coltheart M, Rastle K, Perry C, Langdon R, Ziegler J (2001) DRC: A Dual Route Cascade Model of visual word recognition and reading aloud. Psychol Rev 108(1): 204-256.

46 Pattamadilok, C., Ponz, A., Planton, S. and Bonnard, M. (2016) Contribution of Writing to Reading: Dissociation Between Cognitive and Motor Process in the Left Dorsal Premotor Cortex, Human Brain Mapping, 37:1531-1543

47 Mangen, A. \& Balsvik, L., Pen or keyboard in beginning writing instruction? Some perspectives from embodied cognition, Trends in Neuroscience and Education (in press). 
Figures and tables captions

Table 1. Mean characteristics, writing performance and writing habits in the two samples of participants.

Table 2: Stimuli classification. Summary of the words used in the whole experiment with the number of letters and the ratio of bimanual transitions (expressed as a $\%$ of the total number of transitions within a given word ; for example the word "humour" has one transition from the right to the left hand between " $u$ " and "r" out of 5 so its ratio is $20 \%$ ).

Table 3: Controlled variables in the categories of transition ratio. The Levenshtein distance is a string metric for measuring the difference between two sequences of letters; OLD indexes the mean orthographic similarity between the word and the other words of the lexicon [27], and PLD indexes the phonological similarity between the word and the other words of the lexicon. First letter indexes the rank of the first letter typed with the right hand. We reported means and $\mathrm{p}$ values per category

Table A1: complete results of the mixed models used in the typing task

Table A2: complete results of the mixed models used in the lexical decision task

Fig. 1 Schematic representation of a French AZERTY keyboard. The keys hit by the left and the right hand of an expert typist are colored in red and blue, respectively. For sake of symmetry, the four letters "w", "x", "c" and "v" were not used to compose the words and pseudowords of the study.

Figure 2. Typing task. Response time values (ms) and IKI values (ms) in expert (black) and nonexpert (grey) participants according to the level of difficulty (Rate of bimanual transitions) of the words. Data from 15 have been combined into 3 categories of difficulty (see text). The error bars represent the within-subject confidence intervals [30].

Figure 3. Lexical decision task. RT values (ms) in Expert (black) and Non-Expert (grey) participants according to the level of difficulty (rate of bimanual transitions) of the pseudowords. For clarity, the data have been pooled from 15 into 3 categories of difficulty (see text). The error bars represent the within-subject confidence intervals. 
Dear Editors,

We submit here the original article "Motor expertise for typing impacts lexical decision performance" for consideration in the special issue "Handwriting in a digital age" in Trends in Neuroscience and Education. This research presents data that suggest that the way usually write (or type) might impact linguistic processes as those of recognizing words and pseudowords. We assessed the word recognition abilities by the way of a lexical decision task in two groups of adults differing by their level of expertise in typing. The results show that expert and non-expert typists did not discriminate pseudowords in the same manner. We conclude that replacing handwriting by typing at school could therefore impact reading processes. We look forward to hearing the feedback on this research.

Sincerely,

Marieke Longcamp, 


\begin{tabular}{|l|c|c|}
\hline & Experts (N=17) & Non-experts (N=15) \\
\hline Mean age & 41.7 & 43.6 \\
\hline Daily handwriting time (minutes) & 60.7 & 97.1 \\
\hline Daily typing time (minutes) & 265 & 137.5 \\
\hline Typing experience (years) & 24 & 16.6 \\
\hline Right handed (\%) & 70 & 90 \\
\hline Typing accuracy (\%) & 90 & 90 \\
\hline Typing rate (wpm) & 40.6 & 28.5 \\
\hline
\end{tabular}

Table 1 


\begin{tabular}{|c|c|c|c|}
\hline & 32 six letters words & 40 seven letters words & 48 eight letters words \\
\hline \multirow{6}{*}{$\begin{array}{c}\text { Percentage of } \\
\text { bimanual } \\
\text { transitions }\end{array}$} & $20 \%$ - 8 words (i.e. humour) & $16 \%$ - 8 words (i.e. plumier) & $\begin{array}{l}14 \% \text { - } 8 \text { words (i.e. } \\
\text { pompiste) }\end{array}$ \\
\hline & $40 \%-8$ words (i.e. rayure) & $33 \%-8$ words (i.e. mouflon) & $\begin{array}{l}28 \%-8 \text { words (i.e. } \\
\text { pingouin) }\end{array}$ \\
\hline & $\begin{array}{l}60 \% \text { - } 8 \text { words (i.e. } \\
\text { madame) }\end{array}$ & $50 \%$ - 8 words (i.e. gourdin) & $42 \%-8$ words (i.e. peuplier) \\
\hline & $80 \%-8$ words (i.e. rumeur) & $66 \%$ - 8 words (i.e. typique) & $57 \%-8$ words (i.e. infusion) \\
\hline & & $83 \%$ - 8 words (i.e. plaisir) & $71 \%$ - 8 words (i.e. jalousie) \\
\hline & & & $85 \%$ - 8 words (i.e. habituel) \\
\hline
\end{tabular}

Table 2 


\begin{tabular}{|c|c|c|c|c|c|c|c|c|c|c|}
\hline transitions ratio & Consistency & Frequency & First letter & Nb syllables & Freq Bigrams & $\mathrm{Nb}$ phonemes & Old20 & Pld20 & $\mathrm{Nb}$ right letters & $\mathrm{Nb}$ left letters \\
\hline & \multicolumn{10}{|c|}{ Means } \\
\hline 14 & 83.59 & 12.53 & 7 & 2.50 & 1332.96 & 6.50 & 2.63 & 2.31 & 4.38 & 3.63 \\
\hline 16 & 80.04 & 26.98 & 5 & 1.88 & 1038.78 & 5.25 & 2.16 & 1.91 & 3.38 & 3.63 \\
\hline 20 & 82.72 & 23.28 & 6 & 1.88 & 1212.65 & 4.38 & 1.93 & 1.71 & 3.00 & 3.00 \\
\hline 33 & 68.06 & 18.12 & 3 & 2.00 & 1418.41 & 5.00 & 2.15 & 1.81 & 3.50 & 3.50 \\
\hline 40 & 86.69 & 45.49 & 6 & 1.88 & 1098.68 & 4.88 & 1.87 & 1.56 & 3.00 & 3.00 \\
\hline 42 & 81.63 & 17.86 & 7 & 2.38 & 1422.50 & 6.63 & 2.45 & 2.26 & 4.00 & 4.00 \\
\hline 50 & 82.24 & 48.88 & 6 & 2.25 & 1099.11 & 5.75 & 2.34 & 2.13 & 3.50 & 3.50 \\
\hline 57 & 78.65 & 25.47 & 3 & 2.50 & 1609.06 & 6.13 & 2.53 & 2.04 & 3.88 & 4.13 \\
\hline 60 & 82.53 & 55.87 & 6 & 2.13 & 1327.98 & 5.13 & 2.15 & 1.99 & 3.00 & 3.00 \\
\hline 66 & 82.16 & 45.46 & 3 & 2.38 & 1327.14 & 5.88 & 2.20 & 2.05 & 3.50 & 3.50 \\
\hline 71 & 80.02 & 20.24 & 7 & 2.63 & 1617.81 & 6.13 & 2.39 & 1.78 & 4.00 & 4.00 \\
\hline 80 & 79.15 & 36.42 & 4 & 2.00 & 1178.20 & 4.38 & 1.91 & 1.72 & 3.00 & 3.00 \\
\hline 83 & 85.00 & 40.58 & 8 & 2.25 & 1455.46 & 5.88 & 2.04 & 2.01 & 3.50 & 3.50 \\
\hline 85 & 82.89 & 15.16 & 1 & 2.50 & 1912.56 & 5.88 & 2.05 & 1.68 & 3.88 & 4.13 \\
\hline$F$ value & 0.25 & 0.96 & 0.84 & 1.8 & 6.8 & 0.004 & 4.0 & 3.0 & 0.03 & 0.01 \\
\hline$p$ value & ns & ns & ns & ns & $\mathrm{p}<0.05$ & ns & $p<0.05$ & ns & ns & ns \\
\hline
\end{tabular}

Table 3 
Appendix: Table A1

\begin{tabular}{|c|c|c|c|c|}
\hline \multicolumn{5}{|c|}{ Typing task - IKIs mean } \\
\hline & $\beta$ & SE & t value & $p$ value \\
\hline $\mathrm{Nb}$. letters & -0.016 & 0.008 & -1.9 & $=0.05$ \\
\hline Frequency & -0.0004 & 0.0001 & -4.4 & $<0.001$ \\
\hline Bigrams Frequency & -0.00006 & 0.00001 & -5.4 & $<0.001$ \\
\hline Old20 & 0.06 & 0.01 & 4.3 & $<0.001$ \\
\hline First letter & -0.03 & 0.01 & 2.8 & $<0.01$ \\
\hline Groups & 0.2 & 0.06 & 3.3 & $<0.01$ \\
\hline Transitions & -0.002 & 0.0003 & -6.7 & $<0.001$ \\
\hline Transitions X Group & 0.003 & 0.0002 & 16.6 & $<0.001$ \\
\hline \multicolumn{5}{|c|}{ Typing task - Expert typists group } \\
\hline & $\beta$ & SE & t value & $p$ value \\
\hline Frequency & -0.0005 & 0.0001 & -4.1 & $<0.001$ \\
\hline Bigrams Frequency & -0.00008 & 0.00001 & -6.2 & $<0.001$ \\
\hline Old20 & 0.07 & 0.01 & 4.7 & $<0.001$ \\
\hline First letter & 0.04 & 0.01 & 2.9 & $<0.01$ \\
\hline Transitions & -0.002 & 0.0003 & -5.7 & $<0.001$ \\
\hline \multicolumn{5}{|c|}{ Typing task - Non-expert typists group } \\
\hline & $\beta$ & SE & t value & $p$ value \\
\hline Frequency & -0.0003 & 0.0001 & -2.9 & $<0.01$ \\
\hline Bigrams Frequency & -0.00007 & 0.00001 & -5.5 & $<0.001$ \\
\hline Transitions & 0.001 & 0.0003 & 5.1 & $<0.001$ \\
\hline \multicolumn{5}{|c|}{ Typing task - Reaction times } \\
\hline & $\beta$ & SE & t value & $p$ value \\
\hline Nb. phonemes & -0.02 & 0.009 & -2.3 & $<0.05$ \\
\hline Frequency & -0.0004 & 0.0001 & -3.2 & $<0.01$ \\
\hline Bigrams Frequency & -0.00005 & 0.00001 & -3.0 & $<0.01$ \\
\hline Old20 & 0.05 & 0.02 & 2.6 & $<0.01$ \\
\hline First letter & -0.05 & 0.02 & -3.3 & $<0.01$ \\
\hline Groups & 0.2 & 0.04 & 5.5 & $<0.001$ \\
\hline Transitions & 0.0005 & 0.0004 & 1.3 & ns \\
\hline Transitions X Groups & 0.0001 & 0.0002 & 0.5 & ns \\
\hline
\end{tabular}


Appendix: Table A2.

\begin{tabular}{|c|c|c|c|c|}
\hline \multicolumn{5}{|c|}{ Lexical Decision } \\
\hline & $\beta$ & SE & t value & $p$ value \\
\hline Trial rank & -0.00007 & 0.000008 & -9.9 & $<0.001$ \\
\hline Frequency & -0.004 & 0.00009 & -4.5 & $<0.001$ \\
\hline $\mathrm{Nb}$. letters & 0.01 & 0.007 & 2.3 & $<0.05$ \\
\hline Lexicality & -0.16 & 0.03 & -5.9 & $<0.001$ \\
\hline Groups & -0.02 & 0.05 & -0.4 & ns \\
\hline Transitions & -0.0004 & 0.0003 & -1.2 & ns \\
\hline Transitions X Groups & 0.0006 & 0.0003 & 2.45 & $<0.05$ \\
\hline $\begin{array}{l}\text { Lexicality X Transitions } \\
\text { X Groups }\end{array}$ & -0.0007 & 0.0004 & -1.8 & $=0.06$ \\
\hline \multicolumn{5}{|c|}{ Lexical Decision - Pseudowords } \\
\hline & $\beta$ & SE & t value & $p$ value \\
\hline Trial rank & -0.0001 & 0.00001 & -9.05 & $<0.001$ \\
\hline Nb. letters & 0.03 & 0.007 & 3.7 & $<0.001$ \\
\hline Groups & -0.02 & 0.06 & -0.4 & ns \\
\hline Transitions & -0.0003 & 0.0003 & -1.6 & ns \\
\hline Transitions X Groups & 0.0006 & 0.0002 & 2.6 & $<0.01$ \\
\hline \multicolumn{5}{|c|}{ Lexical Decision - Words } \\
\hline & $\beta$ & SE & t value & $p$ value \\
\hline Trial rank & -0.00006 & 0.00001 & -5.4 & $<0.001$ \\
\hline Frequency & -0.0007 & 0.0001 & -4.8 & $<0.001$ \\
\hline Old20 & 0.07 & 0.02 & 3.5 & $<0.001$ \\
\hline Groups & 0.03 & 0.05 & 0.5 & ns \\
\hline Transitions & 0.0004 & 0.0004 & 1.2 & ns \\
\hline Transitions X Groups & 0.00004 & 0.0002 & 0.2 & ns \\
\hline
\end{tabular}




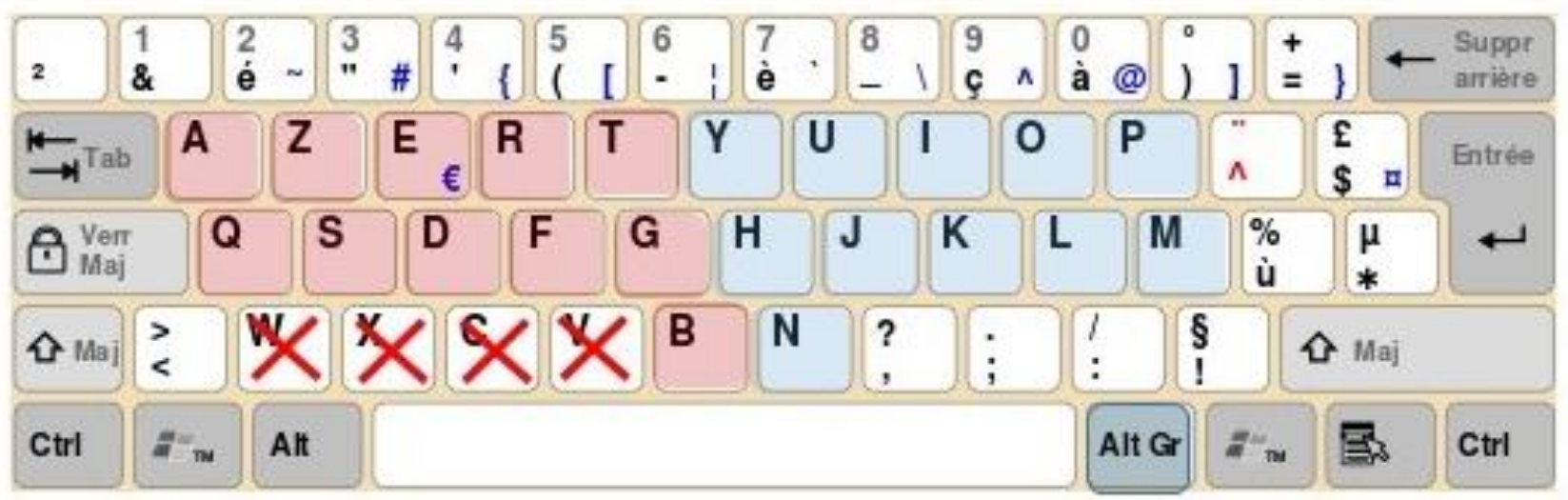

Figure 1 

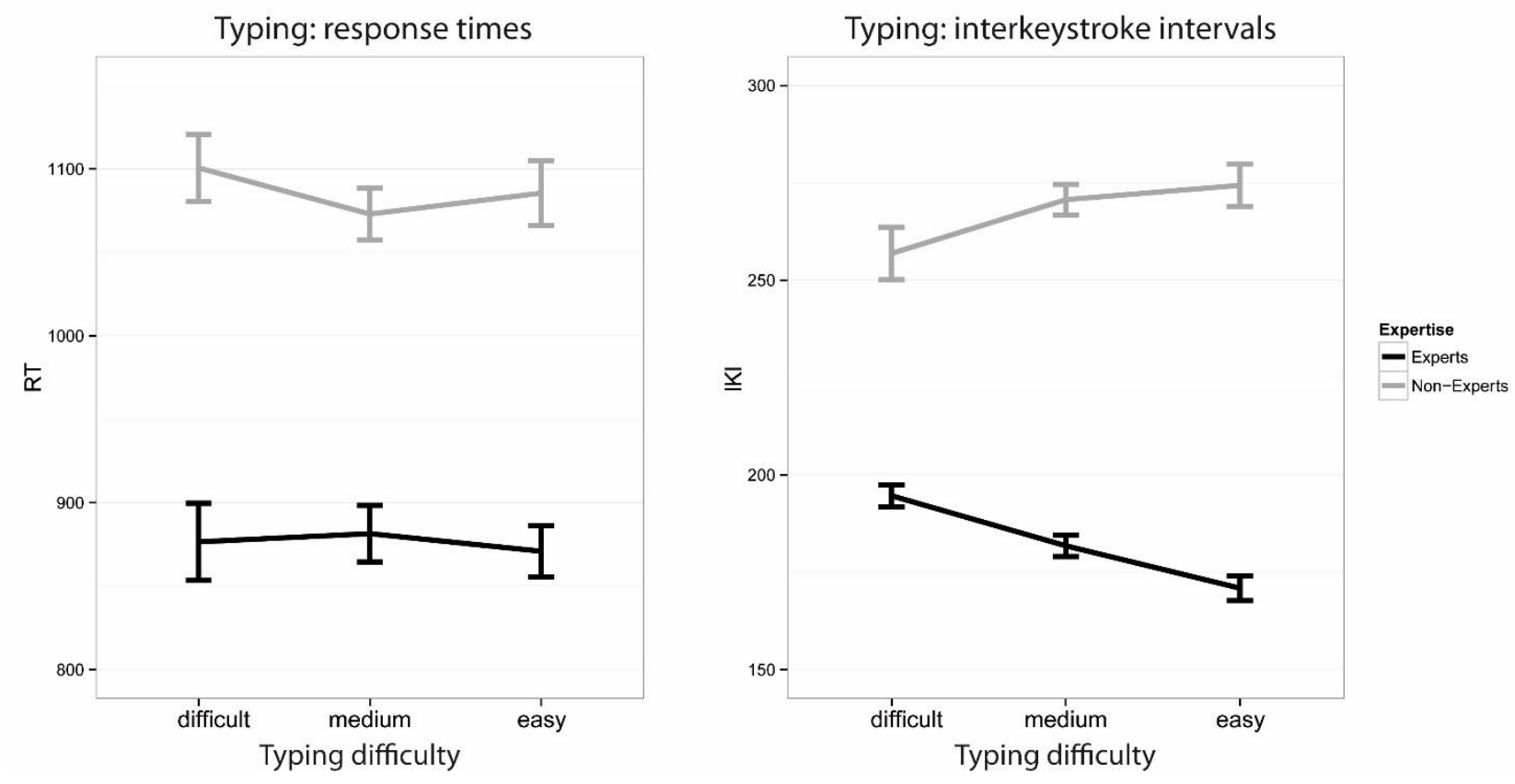

Figure 2 


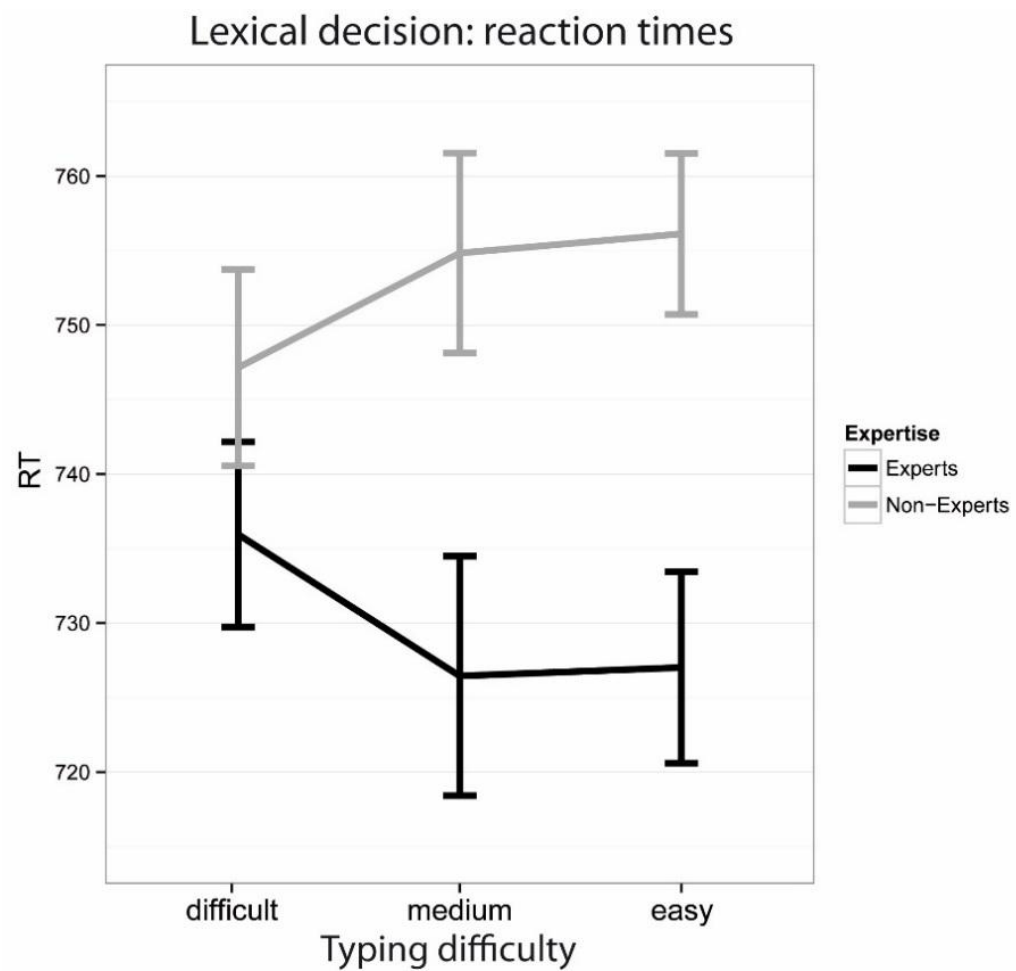

Figure 3 